\title{
Carboprost Tromethamine
}

National Cancer Institute

\section{Source}

National Cancer Institute. Carboprost Tromethamine. NCI Thesaurus. Code C47433.

The tromethamine salt of the (15S)-15 methyl analogue of naturally occurring prostaglandin F2 alpha (PGF2 alpha) with oxytocic activity. Mimicking endogenous PGF2 alpha, carboprost activates prostaglandin $\mathrm{F}$ receptor, a G-protein coupled receptor, on smooth muscle cells, thereby resulting in smooth muscle contractions. When administered intramuscularly on gravid subjects, this agent induces myometrium contractions, thereby initiating luteolysis and consequently parturition. Furthermore, carboprost's action on vascular smooth muscle and gastrointestinal tract sphincters leads to raised blood pressure and induces vomiting or diarrhea, respectively. 